techniques of measuring charge transfer efficiencies and on the effects of surface states at the semiconductor surface on these transfer efficiencies. The latter problem has in fact led to the development of the so-called peristaltic CCDs. Dr L. J. M. Esser (Philips) described how the charge packets in these devices (majority carriers rather than minority carriers) are held away from the semiconductor surface in drift fields which are an order of magnitude higher than those in conventional CCDs. This has led to experimental four-phase devices with charge losses per transfer of less than $10^{-4} \%$ at clock frequencies of more than $100 \mathrm{MHz}$ and to the prospects of operation at microwave frequencies.

The meeting was brought to a close by the chairman, Dr F. H. Reynolds (Post Office Research Station, Dollis Hill), who pointed out the lack of discussion at the meeting of the technology required to make CCDs. This, he suggested, indicates that people are confident that the present difficulties encountered in, for example, defining several centimetres of inter-electrode gaps only $2 \mu \mathrm{m}$ wide in the $100 \times 100$ arrays would be overcome and that large area arrays would become available in the relatively near future at prices much below the present level of around $£ 1$ per bit. Nobody was prepared to commit themselves to saying that a particular technology or particular clocking system was the "best", although it does seem likely that at present the most promising applications of CCDs are in the fields of imaging.

\section{PARTICLE DETECTORS Wiping Clean}

Charged particle tracks can now be recorded, and erased at will, with a specially modified crystal of strontium titanate. All that has to be done to remove any trace of, for example, an alpha particle is to heat the crystal to $900^{\circ} \mathrm{C}$ in a partial vacuum. This is reported by Ouseph in a recent issue of Physical Review Letters (30, 1162; 1973).

To manufacture one of these crystals about $0.1 \%$ of the titanium ions in a normal crystal of strontium titanate have to be replaced with iron ions, about half of which are $\mathrm{Fe}^{4+}$ and half $\mathrm{Fe}^{3+}$. Such a crystal is black because $\mathrm{Fe}^{4+}$ ions cut out visible light.

If, however, the balance is disturbed in favour of $\mathrm{Fe}^{3+}$ the colour of the crystal changes to yellow because the physical properties of the $\mathrm{Fe}^{3+}$ ions predominate. In these circumstances there is a movement of negative oxygen ions to maintain charge balance in the crystal as a whole. In fact a higher than average concentration of $\mathrm{Fe}^{4+}$ ions anywhere in the crystal is accompanied by a higher than average concentration of oxygen ions.

If a doped crystal of strontium titanate, about $2 \mathrm{~cm}$ across and $2 \mathrm{~mm}$ thick, is sandwiched between two metal electrodes and a potential difference of $1,000 \mathrm{~V}$ applied across it when the temperature is greater than $100^{\circ} \mathrm{C}$, negative oxygen ions are attracted to the positive electrode and the vicinity of that electrode becomes black because $\mathrm{Fe}^{4+}$ ions also accumulate there.

Because a charged particle passing through this arrangement at room temperature can induce local heating as it slows down and loses energy, blackening will occur on the side of the track to which oxygen ions are attracted by the electric field applied. Unfortunately it is not possible to pick up individual particle tracks with an optical microscope because they are too small, but blackening has been observed by Ouseph by exposing the crystal to a beam of alpha particles from a particle accelerator.

Tracks of single particles can, however, be detected satisfactorily if a thin layer of uranium oxide (about $0.1 \mathrm{~mm}$ ) is put in between the positive electrode and the strontium titanate crystal. Ouseph detected individual alpha particles given off radioactively by the uranium in this layer and he explains

\title{
Worldwide Marine Sedimentary Hiatuses
}

A Hiatus in a sedimentary column, a well known geological phenomenon in both marine and continental environments, may be recognized by a discontinuity in palaeontologically determined ages, an abrupt and distinct decrease in sedimentation rate, or both. Moreover, where sedimentation ceases completely for a period during which erosion may take place, a surface of unconformity may form to mark the hiatus more clearly. But as far as physical causes are concerned, the hiatus is, in a sense, asymmetrical. The change from sedimentation to non-deposition or erosion may represent the reaching of an erosional level which does not necessarily correspond to the beginning of an associated physical event. By contrast, the end of a hiatus must mark the end of the physical event.

In Nature Physical Science next Monday (July 9), Rona presents an analysis of marine sedimentary hiatuses in terms of physical causes. The Deep Sea Drilling Project (DSDP) has revealed the presence of hiatuses up to tens of millions of years long in all the principal ocean basins, and in the Atlantic, Pacific and Indian Oceans and the Caribbean Sea hiatuses are recognized at 51 out of 171 sites. Rona shows that two of the hiatuses are apparently synchronous throughout the principal basins. The first of these involves more than half of the Palaeocene and ends during the Palaeocene or early Eocene; the second occupies more than half of this in terms of the release of positive oxygen ions by the alpha particles as they slow down in the oxide layer. These ions are then attracted to the surface of the strontium titanate where $\mathrm{Fe}^{4+}$ ions also congregate, and black spots appear, one per alpha particle, which can be seen with a microscope.

Ouseph has also detected a cosmicray particle which travelled lengthways through the oxide layer, approximately parallel to the electrode and the surface of the crystal, releasing oxygen ions as it went and eventually reacting with a nucleus in the same layer.

All these tracks can easily be erased by heating up the crystal to $900^{\circ} \mathrm{C}$ in a partial vacuum, so the device has obvious advantages over photographic emulsions which are widely used by cosmic-ray physicists to detect charged particles but which cannot be recycled.

Ouseph also points out that the new method, although at an early stage of development, evidently has the same advantages over particle detectors like cloud chambers and bubble chambers as do photographic emulsions - it is continously sensitive and does not have to be triggered when it is required to record the passage of particles.

the Oligocene and ends during the early to middle Miocene.

Because these two hiatuses are worldwide, their endings must mark the completion of physical events of worldwide extent. Rona suggests that these physical events are eustatic changes of sea level. The Palaeocene hiatus corresponds to a worldwide reversal from epicontinental marine regression to transgression, and the Oligocene hiatus correlates with a worldwide regression. Such eustatic changes would be expected to lead to "interacting physical and chemical effects on a global scale" and thus to sedimentary hiatuses on a world scale.

The chief physical effect is likely to be changes in ocean circulation leading to erosion by bottom currents. This is supported by the fact that the hiatuses generally lasted longer in the western Atlantic and Pacific basins than in the eastern basins where weaker deep circulation has been predicted. Evidence for associated chemical changes comes from the relatively high average carbonate content of the Palaeoceneearly Eocene Atlantic basin sediments and of Oligocene sediments from both the Atlantic and the Pacific. On the other hand, Rona points out that during the Palaeocene and Oligocene the transfer of sediment from continent to ocean basin would have been relatively large. Thus in spite of the hiatuses, there was a net accumulation of sediment in the ocean basins. 